\title{
Opinion conformity as an impression management tactic following performance of an unpleasant task
}

\author{
MARC RIESS, DONELSON R. FORSYTH, BARRY R. SCHLENKER, and SUSAN FREED \\ University of Florida, Gainesville, Florida 32611
}

\begin{abstract}
Ninety-six subjects were induced to taste unpleasant liquids under conditions of either high or low external justification. In the context of a subsequent interview, subjects rated the task, themselves, and the experimenter for an interviewer who purportedly made positive, negative, or no comments about the task. Subjects rated the liquids as tastier under low- rather than high-justification conditions, thus rationalizing their decision. Also, female subjects under low-justification conditions conformed to the positive comment made by the interviewer by rating the task and the experimenter more favorably. The results support the contention that the social context of dissonance-type experiments is important in understanding attitude change.
\end{abstract}

Attitude change following performance of unpleasant actions has been of considerable interest to social psychologists. Freedman (1963) found that subjects evaluate an unpleasant task more favorably if they are given low rather than high justification for agreeing to perform it. Similarly, Aronson and Mills (1959) found that subjects express greater liking for a boring group if they agree to undergo a severe rather than mild initiation to gain entrance. These studies were initially interpreted from a dissonance perspective. Presumably, subjects change their attitudes to reduce the dissonance generated by faulty decisions made under minimal external justification.

More recent work has focused on the social context of such unpleasant situations (e.g., Alexander \& Knight, 1971; Alexander \& Sagatun, 1973; Forsyth, Riess, \& Schlenker, in press; Schlenker, 1975). These analyses propose that subjects manage the impression they create for the experimenter by attempting to look rational, consistent, and attractive when situational factors might otherwise contradict these images (Tedeschi, Schlenker, \& Bonoma, 1971). Thus, after agreeing to perform a questionable act under conditions where it seems necessary to justify the act (because external justification is minimal), subjects account for the behavior by showing that they liked the task and therefore made a reasonable decision. Such rationalization tactics are also influenced by any statements made by the experimenter concerning the situation, particularly when such statements assist the subject in rationalizing the action. For example, it

The present study was facilitated by the support of the Organizational Effectiveness Research Program, Office of Naval Research (Code 452), under Contract N00014-75-0901; NR 170-797, to the third author. Reprint requests should be sent to Barry Schlenker, Department of Psychology, University of Florida, Gainesville, Florida 32611. Marvin E. Shaw sponsors this paper and takes full editorial responsibility for its content. has been found that subjects display opinion conformity in such situations, agreeing with the opinions of the task stated by an attractive experimenter (Forsyth, et al., in press; Schlenker, 1975).

To further explore the effects of such social context variables, subjects performed an unpleasant task under conditions of high or low justification. After the task, they expected an interview with a psychologist who supposedly had made either favorable, unfavorable, or no comments about the task. Based on an impression management analysis, it was predicted that subjects' ratings of the task would conform to the opinion of the interviewer, but particularly when justification for the behavior was low and the comment was favorable. A favorable comment about the task would allow subjects to voice similar views, thereby making their decision to perform it appear "wise." Under low justification, subjects would have to rationalize the behavior and would be most guided by the comments. When justification was high, there would be little or no reason to rationalize the behavior since it already seemed "wise" given the external justification.

\section{METHOD}

\section{Subjects}

Ninety-six introductory psychology students served as subjects and were run by a female experimenter. Eight subjects participated in each cell of the 2 (high or low justification) by 3 (positive, negative, or no evaluation from the interviewer) by 2 (male or female subject) completely randomized factorial design. The data from five additional subjects were eliminated prior to the analyses, two for experimenter error and three for suspicion.

\section{Procedure}

Upon arrival at the laboratory, subjects were told that the study was investigating "taste sensitivity" and that their physiological reactions to unfamiliar substances would be measured. It was explained that to insure that the substances used would be unfamiliar to the participants, "Liquids that don't taste very good" would be employed. Subjects were therefore given the 
option of not participating. In the high-justification conditions, subjects were told that they would not receive any experimental participation credit if they did not taste the liquids, but could withdraw without prejudice. Subjects in low-justification conditions were told that they would get their full credit (to be applied toward meeting an introductory psychology requirement) regardless of their decision. All subjects in both conditions agreed to participate.

The experimenter attached an electrode to the subject's arm, adjusted the measurement instruments, and blindfolded the subject. He or she then drank the contents of three glasses containing the unpleasant liquids. Pretests had shown that mixtures of (1) Kaopectate and water, (2) castor oil and water, and (3) quinine water were rated negatively by students, and these were employed as the three liquids.

After consuming the liquids, the experimenter explained that the study was completed. However, since it had taken so little time, subjects were asked if they would agree to participate in a second short study that was being conducted by a clinical psychologist. Supposedly, the clinician was developing a new interview technique and needed people to participate in a brief validating procedure. To insure that all interviews were comparable, he had asked the experimenter's permission to interview people concerning their reactions to the taste study, and the experimenter had agreed. Thus, although the interviewer was ostensibly unrelated to the taste study, he was somewhat familiar with its procedures, since he had interviewed other subjects. In the positive-evaluation conditions, subjects were off-handedly told that the interviewer thought "you're getting a pretty good deal in this taste study" since he considered the credit earned quite valuable. In the negativeevaluation conditions, the interviewer supposedly thought the subjects were "getting a bad deal" since the credit wasn't worth much. Subjects in the no-evaluation conditions did not receive information about the interviewer's comments.

All subjects agreed to participate in the interview, were given their credit, and were escorted to another room. When they arrived, the experimenter noted that the interviewer had apparently stepped out for a minute and asked the subject to wait. Before leaving, the experimenter suggested that during the wait the subject could complete some of the forms on the interviewer's desk that would be used in the interviewing process. The forms, which were described as being completeily confidential and to be seen only by the interviewer, asked subjects to rate the taste study, the experimenter, the liquids, and themselves on 9-point bipolar adjective items. When the forms were completed, the experimenter returned and subjects were debriefed.

\section{RESULTS}

\section{Manipulation Checks}

Interviewer's opinion. The manipulation of the interviewer's evaluation of the credit was effective, as indicated by an evaluation main effect on an item asking how much the interviewer felt the credit was worth $[F(2,84)=41.70, p<.001]$. The negative-evaluation condition ratings were more unfavorable $(p<.05)$ than were the no-evaluation condition ratings, which in turn were more unfavorable $(p<.05)$ than the positive-evaluation condition ratings; means were 4.0 , 6.1 , and 8.1, respectively. All pairwise comparisons following ANOVA employed Duncan's multiple range tests.

Self-ratings. Additional support for the effectiveness of the evaluation manipulation was provided by a main effect of evaluation on subjects' averaged selfratings $[F(2,84)=3.10, p<.05]$. Subjects in the positive-evaluation conditions $(M=7.7)$ rated themselves more favorably $(p<.05)$ on evaluative items such as competent, good, and justified than did subjects in the no-evaluation condition $(M=7.0)$ or the negativeevaluation condition $(M=7.3)$.

Experimenter's manipulativeness. Averaged ratings of experimenter's manipulativeness on such items as manipulative, severe, and hard revealed a main effect of justification $[F(1,84)=4.61, p<.05]$. Subjects in the low-justification conditions $(M=3.9)$ rated the experimenter as less manipulative than did subjects in the high-justification conditions $(M=4.4)$, providing support for the contention that the former did feel less constrained to participate than the latter.

\section{Evaluative Ratings of the Liquids, \\ Task, and Experimenter}

The averaged subject's ratings of how tasty/distasteful each of the liquids was revealed a justification main effect $[F(1,84)=4.08, p<.05]$. Subjects in the lowjustification conditions rated the liquirds as more tasty than did subjects in the high-justification conditions; means were 4.6 and 4.1 , respectively (means could range from 1 to 9, with 1 indicating extremely distasteful).

Averaged ratings of the task (e.g., boring-interesting, worthless-valuable, unenjoyable-enjoyable) and experimenter's attractiveness (e.g., competent-incompetent, good-bad, benevolent-malevolent) each revealed a triple interaction of Justification by Evaluation by Sex $[\mathrm{F}(2,84)=3.02, \mathrm{p}=.05$ and $\mathrm{F}(2,84)=4.23, \mathrm{p}<.05$, respectively]. The means comprising the interactions

Table 1

Means for Justification by Evaluation by Sex Conditions on Ratings of the Task and the Experimenter

\begin{tabular}{|c|c|c|c|c|c|c|}
\hline \multirow[b]{3}{*}{ Justification } & \multicolumn{6}{|c|}{ Conditions } \\
\hline & \multicolumn{2}{|c|}{ Negative Evaluation } & \multicolumn{2}{|c|}{ Positive Evaluation } & \multicolumn{2}{|c|}{ No Evaluation } \\
\hline & Low & High & Low & High & Low & High \\
\hline & & & ask Rat & ent Va & & \\
\hline \multirow[t]{2}{*}{$\begin{array}{l}\text { Females } \\
\text { Males }\end{array}$} & $\begin{array}{l}6.4 \mathrm{ab} \\
6.1_{\mathrm{ab}}\end{array}$ & $\begin{array}{l}6.0_{a} \\
6.6_{a b}\end{array}$ & $\begin{array}{l}7.3_{b} \\
6.1_{a}\end{array}$ & $\begin{array}{l}6.0_{\mathrm{a}} \\
7.0_{\mathrm{ab}}\end{array}$ & $\begin{array}{l}6.6_{\mathrm{ab}} \\
7.0_{\mathrm{ab}}\end{array}$ & $\begin{array}{l}6.6_{\mathrm{ab}} \\
6.2_{\mathrm{ab}}\end{array}$ \\
\hline & \multicolumn{6}{|c|}{ Experimenter Ratings Dependent Variable } \\
\hline $\begin{array}{l}\text { Females } \\
\text { Males }\end{array}$ & $\begin{array}{l}7.1_{\mathrm{abc}} \\
6.8_{\mathrm{ab}}\end{array}$ & $\begin{array}{l}6.9_{\mathrm{ab}} \\
7.3_{\mathrm{bc}}\end{array}$ & $\begin{array}{l}7.9 \mathrm{c} \\
7.3_{\mathrm{bc}}\end{array}$ & $\begin{array}{l}6.8_{\mathrm{ab}} \\
7.4_{\mathrm{bc}}\end{array}$ & $\begin{array}{l}7.1_{\mathrm{ab}} \\
7.4_{\mathrm{bc}}\end{array}$ & $\begin{array}{l}6.9_{\mathrm{ab}} \\
6.3_{\mathrm{a}}\end{array}$ \\
\hline
\end{tabular}

Note-Higher scores indicate more favorable ratings. For each dependent variable, means without a common single-level subscript are significantly different by Duncan's multiple range test. 
are reported in Table 1. Females given low justification rated the task more favorably than females given high justification, but only when the interviewer supposedly gave a positive evaluation of the experiment. No differences were obtained between any of the conditions for males. Experimenter ratings mirrored this pattern; when the interviewer made a positive evaluation, females were more favorable in their ratings under low- rather than high-justification conditions.

\section{DISCUSSION}

Subjects rated the liquids as tastier following low rather than high justification, thus replicating Freedman (1963) and demonstrating that unpleasant acts undertaken for minimal justification are rationalized to show that the decision was "wise." Since the experimenter was rated as less manipulative under low- than high-justification conditions, the effect could also be interpreted as evidence of a "like me, like my stimuli" balance process discussed by Alexander and Sagatun (1973).

As predicted, the confluence of low justification and a positive evaluation of the study by the interviewer produced more positive ratings of both the task and experimenter; but, these predictions held only for females. Under low justification, female subjects rated the task and experimenter most favorably, thereby conforming to the interviewer's opinions and making their decision to participate appear rational. Comparable effects were not obtained following the injection of the negative opinion, perhaps because such an opinion ran counter to showing that the decision to participate was actually a wise and rational one. That is, agreeing with the interviewer's unfavorable evaluation would make subjects look even more irrational for having tasted the unpleasant liquids.

Males did not show the predicted opinion conformity effects. One possible explanation of the sex difference is that females tend to be more conforming and more concerned with the evaluations of others than males (see Shaw, 1976, p. 170 for a review) and have been shown to be more persuasible, possibly because they process verbal information more carefully (McGuire, 1969). Thus, females could be expected to be most affected by the interviewer's opinions.

Although the effects of the interviewer's evaluations were anticipated on ratings of the tastiness of the liquids as well as on overall ratings of the task and experimenter, the evaluation affected only ratings of the latter. Retrospectively, it appears that the specificity of effects might have been obtained due to the nature of the interviewer's supposed opinion. The interviewer's opinion pertained to the worth of the credit relative to the task, and not to the tastiness of the liquids per se. Thus, when opinion conformity was found, it was relevant to the interviewer's comments regarding the task as a whole and to the fairness of the experimenter, but not to the more specific ratings of the liquids.

\section{REFERENCES}

Alexander, C. N., \& Knight, P. Situated identities and social psychological experimentation. Sociometry, 1971, 34, 65-82.

Alexander, C. N., \& Sagatun, I. An attributional analysis of experimental norms. Sociometry, 1973, 36, 127-142.

Aronson, E., \& Mills, J. The effect of severity of initiation on liking for a group. Journal of Abnormal and Social Psychology, 1959, 59, 177-181.

Forsyth, D. R., Riess, M., \& SChlenkeR, B. R. Impression management concerns governing reactions to a faulty decision. Representative Research in Social Psychology, in press.

Freedman, J. L. Attitudinal effects of inadequate justification. Journal of Personality, 1963, 31, 371-385.

McGuire, W. J. The nature of attitudes and attitude change. In G. Lindzey \& E. Aronson (Eds.), Handbook of social psychology (Vol. 1). Reading, Mass: Addison-Wesley, 1969.

SCHLENKER, B. R. Liking for a group following an initiation: Impression management or dissonance reduction? Sociometry, 1975, 38, 99-118.

SHAw, M. E. Group dynamics: The psychology of small group behavior. New York: McGraw-Hill, 1976.

Tedeschi, J. T., Schlenker, B. R., \& Bonoma, T. V. Cognitive dissonance: Private ratiocination or public spectacle? American Psychologist, 1971, 26, 685-695.

(Received for publication October 18, 1976.) 